\title{
Erratum to: Understanding and Integrating Local Perceptions of Trees and Forests into Incentives for Sustainable Landscape Management
}

Jean-Laurent Pfund · John Daniel Watts $\cdot$ Manuel Boissière $\cdot$ Amandine Boucard Renee Marie Bullock · Andree Ekadinata $\cdot$ Sonya Dewi $\cdot$ Laurène Feintrenie Patrice Levang $\cdot$ Salla Rantala $\cdot$ Douglas Sheil $\cdot$ Terry Sunderland

Zora Lea Urech

Published online: 7 July 2011

(C) Springer Science+Business Media, LLC 2011

Erratum to: Environmental Management (2011)

DOI 10.1007/s00267-011-9689-1

The name of the author Terry Sunderland was incorrect in the online version of this article. It is presented correctly here.

The online version of the original article can be found under doi: 10.1007/s00267-011-9689-1.

J.-L. Pfund $(\bowtie) \cdot$ M. Boissière · A. Ekadinata $\cdot$ S. Dewi ·

L. Feintrenie $\cdot$ P. Levang · D. Sheil · T. Sunderland

CIFOR, JL CIFOR Situ Gede, Bogor 16000, Indonesia

e-mail: j.pfund@cgiar.org

J. D. Watts · A. Boucard

CIFOR, Luang Prabang, Lao People's Democratic Republic

R. M. Bullock

University of Florida, Gainesville, FL, USA

S. Rantala

ICRAF, Nairobi, Kenya

Z. L. Urech

ETHZ, Zurich, Switzerland 